Reviu Akuntansi dan Bisnis Indonesia, Vol. 1 No. 1, Hlm: 47-56, Juli 2017

Website: http://journal.umy.ac.id/index.php/rab

\title{
Pengaruh Dewan Komisaris dan Leverage Terhadap Environmental Disclosure
}

\author{
Mardhiyah Mutmainah; Arum Indrasari \\ Program Studi Akuntansi Univeritas Muhammadiyah Yogyakarta. \\ I N F O A R T I K E L \\ Kata Kunci: \\ Ukuran dewan komisaris, \\ proporsi dewan \\ independen, jumlah rapat \\ dewan, leverage, \\ environmental disclosure. \\ Jenis Artikel: \\ Penelitian Empiris \\ Correspondence: \\ arum.indrasari@umy.ac.id

\begin{abstract}
A B S T RA K
Penelitian ini bertujuan untuk menguji faktor-faktor yang mempengaruhi enviromental disclosure. Pengukuran enviromental disclosure di perusahaan penelitian ini menggunakan Global Reporting Initiative (GRI). Variabel bebas dalam penelitian ini adalah ukuran dewan komisaris, proporsi dewan komisaris independen, jumlah rapat dewan direksi, dan leverage. Populasi penelitian ini adalah perusahaan manufaktur yang terdaftar di Bursa Efek Indonesia (BEI) pada tahun 2013-2015. Pemilihan sampel penelitian ini menggunakan metode purposive sampling, yaitu perusahaan yang menerbitkan laporan tahunan. Berdasarkan metode purposive sampling, jumlah sampel yang diperoleh adalah 159 perusahaan sampel. Analisis penelitian ini menggunakan analisis regresi berganda menggunakan SPSS15.0. Hasil penelitian ini menunjukkan bahwa ukuran dewan komisaris dan jumlah pertemuan dewan memiliki pengaruh positif terhadap pengungkapan lingkungan. Proporsi dewan independen dan
\end{abstract} \\ leverage tidak mempengaruhi enviromental disclosure.
}

(C) 2019 RAB. Published by Universitas Muhammadiyah Yogyakarta

\section{PENDAHULUAN}

Perusahaan umumnya menjadikan laba sebagai fokus utama. Padahal tanggung jawab perusahaan tidak hanya menghasilkan laba, tetapi juga harus memperhatikan dampak

aktivitasnya, baik lingkungan maupun sosial. Salah satu dampak aktivitas perusahaan adalah terjadinya kerusakan lingkungan. Kerusakan lingkungan terjadi karena perilaku perusahaan yang hanya mementingkan keuntungan bisnis dan tidak menghiraukan terjadinya kerusakan yang mengakibatkan sumber daya alam tidak terbaharukan (Wintoro, 2012).

Pengungkapan (disclosure) yang dilakukan oleh perusahaan adalah alat yang penting untuk mengkomunikasikan kinerja ekonomi, lingkungan hidup dan sosial suatu perusahaan (Agrifood, 2004). Disclosure meliputi ketersediaan informasi keuangan dan non-keuangan berkaitan dengan interaksi organisasi dengan lingkungan fisik dan lingkungan sosialnya, dapat dibuat di dalam laporan tahunan perusahaan (annual report) atau laporan sosial terpisah (Guthrie \& Parker,1990). Penerapan pengungkapan bertujuan memberikan gambaran mengenai kondisi dan aktivitas yang terjadi dalam perusahaan untuk mempermudah pembuatan laporan tahunan.

Environmental disclosure merupakan pengungkapan informasi yang berkaitan dengan lingkungan di dalam laporan tahunan perusahaan (Suratno et.al., 2006). Brown dan Deegan (1998) mengatakan environmental disclosure penting untuk dilakukan karena melalui pengungkapan lingkungan hidup pada laporan tahunan perusahaan, masyarakat dapat memantau aktivitas-aktivitas yang dilakukan oleh perusahaan dalam rangka memenuhi tanggung jawab sosialnya. Dengan cara demikian, perusahaan akan memperoleh manfaat positif yakni perhatian, kepercayaan dan 
dukungan dari masyarakat. Tujuan environmental disclosure adalah untuk memberikan informasi yang relevan dan signifikan untuk pengambilan keputusan para pengguna laporan keuangan.

Environmental disclosure dalam laporan tahunan masih bersifat sukarela, sehingga ada atau tidaknya pengungkapan ini di dalam laporan tahunan sebuah perusahaan bergantung pada masingmasing perusahaan itu sendiri. Di Indonesia, dalam standar akuntansi keuangan belum mewajibkan semua perusahaan untuk mengungkapkan informasi lingkungan hidup, akibat dari itu, banyak dari perusahaan yang tidak mengungkapkan informasi lingkungan hidupnya.

Dewan komisaris berkewajiban memberi nasehat kepada dewan direksi, serta menjalankan serangkaian keputusan dan bertanggung jawab sebagai pengawasan. Secara umum dewan komisaris independen mempunyai pengawasan yang lebih baik terhadap manajemen yang mana dapat meminimalisir adanya kemungkinan munculnya kecurangan dalam menyajikan laporan keuangan yang dilakukan oleh manajer. Semakin kompeten dewan komisaris maka akan semakin mengurangi adanya kecurangan dalam laporan keuangan dan pengungkapan lingkungan dalam perusahaan. Fungsi pengawasan dan pemberian nasihat dewan komisaris mencakup tindakan pencegahan, perbaikan, sampai kepada pemberhentian sementara. Proporsi komisaris independen atas jumlah seluruh anggota dewan komisaris merupakan variabel yang sering digunakan untuk menguji pengaruh corporate governance terhadap environmental disclosure. Hasil penelitian oleh Ariningtika (2013), menemukan hasil bahwa proporsi dewan komisaris independen berpengaruh positif secara signifikan terhadap environmental disclosure. Namun bertentangan dengan penelitian yang dilakukan oleh Effendi, dkk (2012) menyatakan bahwa proporsi dewan komisaris independen tidak berpengaruh positif terhadap environmental disclosure.

Rapat dewan komisaris merupakan kewajiban dari dewan komisaris untuk menjalankan serangkaian keputusan bersama dengan sejumlah rapat tentang kebijakan perusahaan yang akan dijalankan. Menurut penelitian yang dilakukan oleh Brick dan Chidambaran, (2007), semakin banyak rapat yang diselenggarakan dewan komisaris akan semakin meningkatkan kinerja perusahaan. Penelitian yang dilakukan oleh Setyawan dan Zulaikha, (2012), dan Ariningtika, dkk (2013), menyatakan jumlah rapat dewan komisaris berpengaruh signifikan terhadap environmental disclosure. Namun bertentangan dengan penelitian yang dilakukan oleh Effendi, dkk (2012) menyatakan bahwa jumlah rapat dewan komisaris tidak berpengaruh terhadap environmental disclosure.

Suhardjanto (2010) melakukan investigasi pengaruh leverage terhadap pengungkapan lingkungan. Hasil yang diperoleh dari penelitian Suhardjanto (2010) menemukan adanya pengaruh leverage terhadap pengungkapan lingkungan, sementara hasil yang berbeda ditunjukan oleh Ariningtika (2013) yang tidak menemukan pengaruh antara leverage dengan pengungkapan lingkungan

Penelitian ini merupakan replikasi dari penelitian Effendi et. al (2012) yang meneliti tentang pengaruh dewan komisaris terhadap environmental disclosure pada perusahaan manufaktur yang listing di BEI. Penelitian ini menggunakan sampel tahun 2008-2011, sehingga sebagian besar dari variabel yang digunakan dalam penelitian ini adalah sama, yaitu ukuran dewan komisaris, proporosi dewan komisaris independen dan jumlah rapat dewan komisaris.

Penelitian ini juga replikasi dari penelitian Laras Miranti (2009) yang menguji pengaruh karakteristik perusahaan terhadap environmental disclosure. Karakteristik perusahaan diukur menggunakan leverage. Hasil penelitian menunjukan bahwa leverage tidak berpengaruh terhadap environmental disclosure.

Penelitian ini bertujuan untuk menguji dan memperoleh bukti pengaruh ukuran dewan komisaris, proporsi dewan komisaris independen, jumlah rapat dewan komisaris dan leverage terhadap environmental disclosure. Penelitian ini diharapkan dapat menyajikan bukti empiris mengenai faktor-faktor yang berpengaruh terhadap environmental disclosure. 


\section{TINJAUAN LITERATUR DAN PERUMUSAN HIPOTESIS}

\section{Teori Stakeholder}

Stakeholder merupakan pihak yang mempunyai kepentingan baik dengan pihak internal maupun eksternal yang saling berhubungan dan bersifat mempengaruhi maupun dipengaruhi. Stakeholder terdiri dari karyawan, masyarakat, negara, supplier, pasar modal, pesaing, badan industri, pemerintah asing dan lain-lain. Namun, teori stakeholder berpendapat bahwa ada pihak lain yang terlibat, yaitu lembaga pemerintah, kelompok politik, asosiasi perdagangan, masyarakat, pekerja prospektif, pelanggan prospektif dan publik secara umum. Kadang pesaing pun dapat terhitung sebagai stakeholder (Rochmi, 2007 dalam Handayani, 2010).

Peran stakeholders pada perusahaan sangat berpengaruh untuk mempengaruhi dan menjadikan pertimbangan dalam mengungkapkan suatu informasi di laporan keuangan suatu perusahaan. Stakeholders menjadi tolak ukur dan pertimbangan utama bagi perusahaan karena stakeholder merupakan pemegang posisi yang kuat dalam perusahaan. Stakeholders pada dasarnya dapat mempengaruhi penggunaan berbagai sumber ekonomi yang digunakan dalam aktivitas perusahaan.

\section{Teori Agensi}

Teori Agensi merupakan teori yang mengungkapkan suatu kontrak hubungan antara pemilik atau pemegang saham dan agen atau manajer. Agency relationship merupakan hubungan antara dua pihak, dimana pihak pertama bertindak sebagai prinsipal atau pemberi amanat dan pihak kedua disebut agen yang bertindak sebagai perantara

yang mewakili prinsipal dalam melakukan transaksi dengan pihak ketiga. Pada agency theory yang disebut prinsipal adalah pemegang saham dan yang dimaksud agen adalah manajemen yang mengelola perusahaan.

Teori agensi merupakan hubungan kesepakatan antara pemilik dengan agen guna menghasilkan perjanjian atau kontrak. Dengan ini pemilik ingin mengetahui informasi dan aktifitas manajemen terkait dengan investasi atau dananya dalam perusahaan dan sebagai pertanggungjawaban perusahaan terkait dengan kinerja manajer. Sebagai agen, manajer bertanggung jawab secara moral untuk mengoptimalkan keuntungan para prinsipal, dan manajer juga menginginkan untuk selalu memperoleh kompensasi sesuai dengan yang tertera pada kontrak.

\section{Teori Legitimasi}

Teori legitimasi dilandasi oleh adanya suatu kontrak sosial yang terjadi antara perusahaan dengan masyarakat (Ghozali dan Chariri, 2007). Teori legitimasi dalam kegiatan operasional pada sebuah organisasi diharuskan memperlihatkan perilaku yang konsisten dengan nilai sosial. (Ghozali dan Chariri, 2007) menyatakan bahwa kegiatan perusahaan dapat menimbulkan dampak sosial dan lingkungan, sehingga praktik pengungkapan sosial dan lingkungan merupakan alat manajerial yang digunakan perusahaan untuk menghindari konflik sosial dan lingkungan.

\section{Pengaruh Ukuran Dewan Komisaris dengan Environmental Disclosure}

Dewan komisaris sebagai organ puncak pengelolaan internal perusahaan memiliki peran terhadap aktivitas pengawasan. Sehingga komposisi dewan komisaris menentukan pengungkapan lingkungan. Menurut Coller dan Gregory (1999) dalam Sembiring (2005 bahwa semakin besar jumlah anggota dewan komisaris maka akan semakin mudah untuk mengendalikan CEO dan monitoring yang dilakukan akan semakin efektif. Selain itu juga, keberadaan dewan komisaris yang independen (outside member board) akan semakin menambah efektivitas pengawasan. Komposisi dewan komisaris yang independen umumnya merupakan sebuah solusi untuk mengatasi masalah kegaenan 
Hasil penelitian oleh Sun, et.al (2010) dan Sagala, (2013), menemukan hasil bahwa ukuran dewan komisaris berpengaruh positif secara signifikan terhadap environmental disclosure. Namun bertentangan dengan penelitian yang dilakukan oleh Effendi, dkk (2012) menyatakan bahwa ukuran dewan komisaris tidak berpengaruh berpengaruh positif terhadap environmental disclosure.

Peran teori stakeholder disini yakni ukuran dewan komisaris yang lebih besar dapat menutup kelemahan asimetri informasi karena dengan memiliki banyak anggota dewan komisaris maka semakin banyak pula ide, pengalaman, dan adanya interaksi antar dewan komisaris yang mendukung proses pengawasan terhadap manajemen perusahaan. Pengawasan tersebut berfungsi agar di dalam melakukan kegiatan bisnisnya perusahaan tetap transparan sehingga mendapat respon yang positif dari para stakeholder-nya (Sanjaya,2013). Berdasarkan uraian diatas maka dapat dikembangkan hipotesis sebagai berikut:

\section{$\boldsymbol{H}_{I} \quad$ : Ukuran dewan komisaris perusahan berpengaruh positif terhadap Environmental Disclosure.}

\section{Pengaruh Proporsi Dewan Komisaris Independen dengan Environmental Disclosure}

Peran utama dewan komisaris adalah terkait dengan fungsi kontrol (Pound, 1995 dalam Effendi et al., 2012). Dewan komisaris independen merupakan alat untuk mengawasi perilaku manajemen untuk meningkatkan pengungkapan informasi sukarela dalam laporan tahunan perusahaan (Rosenstein dan Wyatt, 1990). Lebih jauh lagi Choiriyah (2010) dan Uwuigbe et.al. (2011) menyatakan bahwa proporsi dewan komisaris berpengaruh positif terhadap environmental disclosure.

Proporsi komisaris independen atas jumlah seluruh anggota dewan komisaris merupakan variabel yang sering digunakan untuk menguji pengaruh corporate governance terhadap environmental disclosure. penelitian yang dilakukan oleh Uwuigbe, et.al (2011) dan Ariningtika, dkk (2013), menyatakan bahwa proporsi dewan komisaris independen berpengaruh positif Signifikan terhadap environmental disclosure. Namun penelitian ini bertentangan ini dengan penelitian yang dilakukan oleh Effendi, dkk (2012), dan Sagala, (2013), menyatakan bahwa proporsi dewan komisaris independen tidak berpengaruh terhadap environmental disclosure.

Tanggung jawab perusahaan terhadap para stakeholder yaitu dengan melakukan pengungkapan lingkungan untuk memberikan informasi kepada masyarakat (stakeholder) mengenai kinerja lingkungan perusahaan merupakan perwujudan dari asas transparansi. Hasil ini sejalan dengan hasil dari Uwuigbe et al. (2011) dan Suhardjanto dan Permatasari (2010), yang menunjukan bahwa fungsi dari dewan komisaris independen dapat mengawasi perilaku manajemen untuk meningkatkan pengungkapan lingkungan dalam laporan tahunannya. Berdasarkan uraian diatas maka dapat dikembangkan hipotesis sebagai berikut:

\section{$\boldsymbol{H}_{2}$ : Proporsi dewan komisaris independen berpengaruh positif terhadap environmental disclosure.}

\section{Pengaruh Jumlah Rapat Dewan Komisaris dengan Environmental Disclosure}

Tujuan dari rapat dewan komisaris adalah untuk mengarahkan dan mengevaluasi aktifitas yang dilakukan oleh perusahaan dan juga rapat dewan komisaris harus dilakukan secara berkala agar dapat memantau aktifitas yang berhubungan dengan environmental disclosure.

Jensen dan Meckling (1976) menyebutkan hubungan keagenan sebagai kontrak di antara principal (pemegang saham) dan agen (manajer) dimana principal mendelegasikan pengambilan keputusan kepada agen. Sebagai agen, manajer secara moral bertanggung jawab untuk mengoptimalkan keuntungan para pemilik (principal) dan sebagai imbalannya akan memperoleh kompensasi sesuai dengan kontrak. Dengan demikian terdapat dua kepentingan yang berbeda di 
dalam perusahaan dimana masing-masing pihak berusaha untuk mencapai atau mempertahankan tingkat kemakmuran yang dikehendaki (Ujiyantho, 2007). Manajer sebagai pengelola perusahaan lebih banyak mengetahui informasi internal dan prospek perusahaan di masa yang akan datang dibandingkan pemilik (pemegang saham). Maka dari itu pentingnya rapat dewan komisaris agar dapat mendiskusikan tentang kebijakan perusahaan agar lebih efektif di masa yang akan datang.

Menurut penelitian yang dilakukan oleh (Brick dan Chidambaran, 2007 dalam Suhardjanto dan Permatasari, 2010), semakin banyak rapat yang diselenggarakan dewan komisaris akan semakin meningkatkan kinerja perusahaan. Oleh karena itu semakin sering dewan komisaris melakukan rapat, maka fungsi pengawasan dewan komisaris semakin efektif dan juga pengungkapan lingkungan pada perusahaan semakin luas. Penelitian yang dilakukan oleh Setyawan dan Zulaikha, (2012), dan Ariningtika, dkk (2013) Menyatakan jumlah rapat dewan komisaris berpengaruh signifikan terhadap environmental disclosure. Namun bertentangan dengan Penelitian yang dilakukan oleh Effendi, dkk (2012) menyatakan bahwa jumlah rapat dewan komisaris tidak berpengaruh terhadap environmental disclosure. Berdasarkan uraian diatas maka dapat dikembangkan hipotesis sebagai berikut:

\section{$\boldsymbol{H}_{3}$ :Jumlah rapat dewan komisaris berpengaruh positif terhadap environmental disclosure.}

\section{Pengaruh Leverage dengan Environmental Disclosure}

Leverage dapat dikatakan sebagai alat untuk mengukur seberapa besar perusahaan tergantung pada kreditor dalam membiayai aset perusahaan (Karina, 2013). Perjanjian terbatas seperti perjanjian utang yang tergambar dalam tingkat leverage dimaksudkan membatasi kemampuan manajemen untuk menciptakan transfer kekayaan antar pemegang saham dan pemegang obligasi (Jensen and Meckling, 1976; Smith and Warner, 1979 dalam Belkaoui and Karpik, 1989).

Semakin besar environmental disclosure maka semakin besar dapat mempengaruhi leverage perusahaan tersebut. Melalui environmental disclosure masyarakat dapat memantau aktivitas yang dilakukan oleh perusahaan. Dengan demikian, perusahaan memperoleh perhatian dan kepercayaan dari masyarakat sehingga perusahaan dapat tetap dipercaya.

Hasil pengujian mendukung berlakunya teori legitimasi, yaitu teori yang menjelaskan adanya suatu kontrak sosial antara perusahaan dengan para stakeholder-nya (Ghozali dan Chariri, 2007). Menurut Deegan (2002) dalam perspektif teori legitimasi, suatu perusahaan akan secara sukarela atau menutupnutupi laporan aktifitasnya sesuai dengan baik atau buruknya tingkat environmental performance perusahaan dan hal ini dapat memperlemah atau memperkuat fungsi pengawasan dari corporate governance. Penelitian yang dilakukan oleh Cormier dan Magnan (2003) menemukan bahwa adanya pengaruh antara leverage dan environmental disclosure. Paramitha (2014) juga menyimpulkan hal yang sama bahwa leverage berpengaruh signifikan atas environmental disclosure. Maka semakin tinggi tingkat leverage perusahaan, semakin rendah pula tingkat pengungkapan informasi terkait lingkungannya. Berdasarkan uraian diatas, maka dapat dikembangkan hipotesis sebagai berikut:

\section{$\boldsymbol{H}_{4} \quad$ : Leverage perusahan berpengaruh negatif terhadap Environmental Disclosure.}

\section{METODE PENELITIAN}

Penilitian ini menggunakan data sekunder. Data sekunder yang digunakan diambil dari penelitian dalam annual report perusahaan manufaktur yang terdapat di Bursa Efek Indonesia pada tahun 2013-2015. Populasi dalam penelitian ini adalah perusahaan manufaktur yang terdaftar di Bursa Efek Indonesia (BEI) pada tahun 2013-2015 (3 tahun). Metode pengambilan sampel yang 
digunakan adalah purpossive sampling, teknik pengambilan sampel perusahaan dalam penelitian dilakukan berdasarkan kriteria sebagai berikut:

1. Perusahaan manufaktur yang terdapat di Bursa Efek Indonesia pada tahun 2013-2015.

2. Perusahaan mempublikasikan laporan tahunan secara lengkap.

3. Perusahaan yang memiliki data-data lengkap yang terkait dengan variable penelitian.

4. Perusahaan yang laporan tahunannya menggunakan satuan rupiah.

Dalam penelitian ini, proses analisis data yang dipergunakan adalah regresi linier berganda (multiple regression) dengan menggunakan program komputer Statistical Product Service Solutions (SPSS). Model regresi berganda yaitu metode statistik berfungsi untuk menguji pengaruh beberapa variabel independen terhadap satu variabel dependen. Model yang digunakan dalam regresi berganda untuk melihat ukuran dewan komisaris, proporsi dewan komisaris independen, jumah rapat dewan komisaris, leverage terhadap environmental disclosure dalam penelitian ini adalah:

$\mathrm{ED}=\alpha 0+\beta 1 \mathrm{UDKOM}+\beta 2 \mathrm{PRODKOM}+\beta 3 \mathrm{JRDK}+\beta 4 \mathrm{LEV}+\mathrm{e}$

Keterangan Persamaan Regresi Berganda

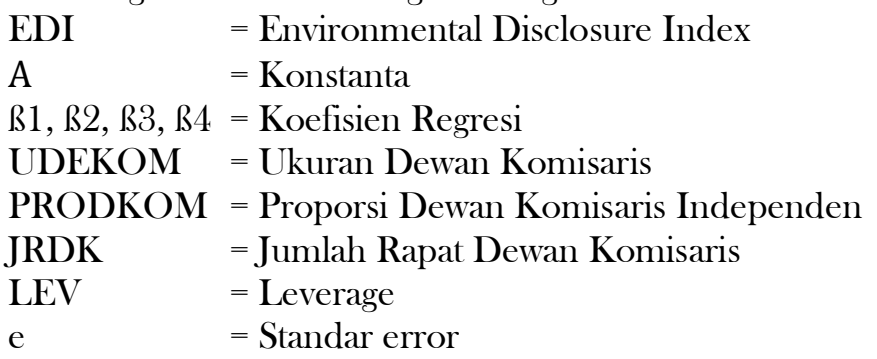

\section{HASIL DAN PEMBAHASAN}

Perusahaan yang menjadi objek dalam penelitian ini adalah perusahaan manufaktur yang terdaftar di Bursa Efek Indonesia (BEI) pada tahun 2013-2015. Berdasarkan metode purposive sampling diperoleh 159 perusahaan manufaktur yang memenuhi kriteria.

Tabel 1 Hasil Pemilihan purposive sampling

Keterangan

2013-2015

Perusahaan Manufaktur yang listing di Bursa Efek Indonesia

Perusahaan yang tidak memiliki Laporan tahunan (annual report) atau

laporan keuangan

Perusahaan Manufaktur yang Delisting

Perusahaan yang tidak memenuhi kriteria sampel terkait dengan variabel penelitian dan tidak menggunakan bahasa indonesia

Perusahaan sampel sebelum ada outlier 


\section{Statistik Deskriptif}

Tabel 2 Hasil Statistik Deskriptif

\begin{tabular}{lccccc}
\hline & $\mathbf{N}$ & Minimum & Maximum & Mean & Std. Deviation \\
\hline UDK & 159 & 2.00 & 12.00 & 4.6289 & 2.11251 \\
PDKI & 159 & .20 & 2.00 & .4649 & .24444 \\
JRDK & 159 & 1.00 & 32.00 & 5.5786 & 4.35219 \\
LEV & 159 & .05 & 1.82 & .4487 & .26319 \\
GRI & 159 & .00 & .33 & .1183 & .09421 \\
Valid N (listwise) & 159 & & & & \\
\hline
\end{tabular}

Sumber : Data Primer

Tabel statistik deskriptif pada setiap variabel penelitian. Jumlah pengamatan dalam penelitian ini adalah 159 sampel. Variabel Environmental Disclosure (EDI) memiliki nilai minimum 0,00; nilai maksimum 0,33; nilai rata-rata 0,1183; dan nilai standar deviasi sebesar 0,09421.

1. Variabel Ukuran Dewan Komisaris (UDK) memiliki nilai minimum 2; nilai maksimum 12; nilai rata-rata 4,6289; dan nilai standar deviasi sebesar 2,11251.

2. Variabel Proporsi Dewan Komisaris Independen (PRODKOM) memiliki nilai minimum 0,20; nilai maksimum 2; nilai rata-rata 0,4649; dan nilai standar deviasi sebesar 0,24444.

3. Variabel Jumlah Rapat Dewan Komisaris (JRDK) memiliki nilai minimum 1; nilai maksimum 32; nilai rata-rata 5,5786; dan nilai standar deviasi sebesar 4,35219.

4. Leverage memiliki nilai minimum 0,05 ; nilai maksimum 0,33 ; nilai rata-rata 0,1183 dan nilai standar deviasi sebesar 0,0942

Model regresi dalam penelitian ini dinyatakan lolos dalam pengujian asumsi klasik, yang terdiri dari uji normalitas, uji multikolinearitas, uji autokorelasi, dan uji heteroskedastisitas. Hasil penelitian menunjukkan nilai adjusted $\mathrm{R}$ square sebesar 0,101 . Hal ini menunjukkan bahwa kemampuan variabel independen dalam mempengaruhi terjadinya environmental disclosure hanya sebesar 10\%, sedangkan $90 \%$ variabel independen dipengaruhi variabel lain di luar model penelitian.

Tabel 3 Hasil Uji Nilai t

\begin{tabular}{|c|c|c|c|c|c|c|}
\hline & \multirow{2}{*}{ Model } & \multicolumn{2}{|c|}{ Unstandardized Coefficients } & \multirow{2}{*}{$\begin{array}{r}\begin{array}{r}\text { Standardized } \\
\text { Coefficients }\end{array} \\
\text { Beta } \\
\end{array}$} & \multirow[t]{2}{*}{$\mathrm{t}$} & \multirow[t]{2}{*}{ Sig. } \\
\hline & & B & Std. Error & & & \\
\hline \multirow[t]{5}{*}{1} & (Constant) & .043 & .026 & & 1.634 & .104 \\
\hline & UDK & .016 & .003 & .353 & 4.598 & .000 \\
\hline & PDKI & -.020 & .031 & -.053 & -.666 & .506 \\
\hline & JRDK & .001 & .002 & .118 & 2.224 & .028 \\
\hline & LEV & .020 & .028 & .055 & .705 & .482 \\
\hline
\end{tabular}

Sumber : Data Primer

\section{Ukuran Dewan Komisaris Terhadap Environmental Disclosure}

Berdasarkan tabel 3 menunjukkan ukuran dewan komisaris memiliki nilai koefisien regresi sebesar 0,016 dengan signifikansi sebesar $0,000<$ alpha $(0,05)$ sehingga ukuran dewan komisaris berpengaruh positif terhadap environmental disclosure. Dengan demikian hipotesis satu diterima. 


\section{Proporsi Dewan Komisaris Independen Terhadap Environmental Disclosure}

Berdasarkan tabel 3 menunjukkan ukuran dewan komisaris memiliki nilai koefisien regresi sebesar -0,020 dengan signifikansi sebesar 0,506 > alpha $(0,05)$ sehingga proporsi dewan komisaris tidak berpengaruh terhadap environmental disclosure. Dengan demikian hipotesis kedua ditolak.

\section{Jumlah Rapat Dewan Komisaris Terhadap Environmental Disclosure}

Berdasarkan tabel 3 menunjukkan jumlah rapat dewan komisaris memiliki nilai koefisien regresi sebesar 0,001 dengan signifikansi sebesar $0,028<$ alpha $(0,05)$ sehingga Jumlah rapat dewan komisaris berpengaruh positif terhadap environmental disclosure. Dengan demikian hipotesis ketiga diterima.

\section{Leverage Terhadap Environmental Disclosure}

Berdasarkan tabel 3 menunjukkan bahwa leverage memiliki nilai koefisien regresi sebesar 0,020 dengan signifikansi sebesar $0,482>$ alpha $(0,05)$ sehingga leverage tidak berpengaruh terhadap environmental disclosure. Dengan demikian hipotesis keempat ditolak.

\section{KETERBATASAN PENELITIAN}

Keterbatasan dalam penelitian ini jangka waktu periode pengamatan hanya tiga tahun dari tahun 2013-2015 sehingga sampel yang digunakan sangat terbatas. Dilihat dari nilai adjusted $\mathbf{R}$ Square sebesar 0,10 atau $10 \%$, berarti masih ada variabel-variabel lain yang dapat diteliti lebih lanjut yang diduga berpengaruh terhadap environmental disclosure. Penelitian ini hanya menggunakan objek penelitian dari perusahaan manufaktur saja sehingga hasil penelitian tidak bisa digeneralisir pada tipe perusahaan lainnya.

\section{KESIMPULAN}

Berdasarkan penelitian dapat diambil kesimpulan pertama ukuran dewan komisaris berpengaruh positif terhadap environmental disclosure, karena ukuran dewan komisaris memberikan pengaruh yang sangat besar dan efektif dalam pengambilan keputusan. Kedua, proporsi dewan komisaris independen berpengaruh negatif terhadap environmental disclosure, karena peran dewan komisaris independen tidak berfungsi dengan baik, kurang berkompeten dan kurang objektif dalam mengatasi dan mengawasi kinerja dari para manajemen. Ketiga, jumlah rapat dewan komisaris berpengaruh positif terhadap environmental disclosure, karena anggota dewan komisaris memberikan pengaruh yang sangat besar dan efektif dalam pengambilan keputusan, mengawasi dan juga sebagai evaluasi. Keempat, leverage berpengaruh negatif terhadap environmental disclosure. Hal ini dikarenakan perusahaan yang memiliki tingkat leverage yang tinggi, maka biasanya manajemen cenderung lebih tertutup dalam melaporkan kinerja perusahaannya.

\section{DAFTAR PUSTAKA}

Ahmad, N.N.N., \& Sulaiman, M. (2004). Environmental Disclosures in Malaysian Annual Reports: A Legitimacy Theory Perspective. IJCM, 14, 44.

Anggraini, R.R. (2006). Pengungkapan Informasi Sosial dan Faktor-Faktor yang Mempengaruhi Pengungkapan Informasi Sosial dalam Laporan Keuangan Tahunan (Studi Empiris pada 
Perusahaan-Perusahaan yang Terdaftar di Bursa Efek Jakarta). Simposium Nasional Akuntansi. IX (Padang).

Ariningtika, P. \& Kiswara, E. (2013). Pengaruh Praktik Tata Kelola Perusahaan yang Baik Tehadap Pegungkapan Lingkungan Perusahaan (Studi Empiris Pada Perusahaan Pertambangan yang Terhadap di Bursa Efek Indonesia Tahun 2010-2011) Diponegoro Journal of Accounting. 2 (2).

Brick E. I. \& Chidambaran N. K. (2007). Board Meetings, Committee Structure, and Firm Performance, http://papers.ssrn.com.

Brown, N. \& Deegan, C. (1998). The Public Disclosure of Environmental Performance Information (A dual Test of Media Agenda Setting Theory and Legitimacy Theory). Accounting and Business Research. 29 (1), 21-41.

Deegan, C. (2002). The Legitimizing Effect Of Social And Environmental Disclosures: A Theoretical Foundation. Accounting, Auditing and Accountability Journal, 15(3), 282-311.

Effendi, B., Uzliwati, L., \& Yulianto, A. S. (2012). Pengaruh Dewan Komisaris Terhadap Environmental Disclosure Pada Perusahaan Manufaktur yang Listing di BEI Tahun 20082011. Simposium Nasional Akuntansi XV.

Eng, L. L., \& Mak, Y. T. (2003). Corporate Governance and Voluntary Disclosure. Jurnal Of Accounting And Public Policy. 22, 325-345

Freedman, M. \& Jaggi, B. (2005). Global Warming, Commitment to the Kyoto Protocol, and Accounting Disclosures by The Largest Global Public Firms From Polluting Industries. The International Journal of Accounting. 40, 215- 232.

Ghozali, I. \& Anis C. (2011). Aplikasi Analisis Multivariate dengan Program IBM SPSS 19. Semarang: Badan Penerbit Universitas Diponegoro.

Gujarati, D. N. (2003). Basic Econometrics. Forth Edition. New York: Mc.Graw-Hill

Guthrie, J. \& Parker, L.D. (1990). Corporate Social Disclosure Practice: A Comparative International Analysis. Advances in Public Interest Accounting, 3, 159-175.

Haniffa, R. M., \& Cooke, T. E. (2005). The Impact of Culture and Governance on Corporate Social Reporting. Journal of Accounting and Public Policy. 24, 391-430

Hayuningtyas, P. (2007). Karakteristik Perusahaan dan Pengungkapan Tanggung Jawab Sosial Perusahaan. Skripsi. FE UNS.

Jensen, M.C., \& Meckling, W.H. (1976). Theory of the Firm: Managerial Behavior, Agency Cost, and Ownership Structure. Journal of Financial Economic, 3, 305-360.

Karina, L. A. D., \& Etna, N. A. Y. (2013). Analisis Faktor-faktor yang Mempengaruhi Pengungkapan CSR. Journal of Accounting, 2 (2), 1-12.

Prawinandi, W., Suhardjanto, D., \& Triatmoko, H. (2012). Peran struktur corporate governance dalam tingkat kepatuhan mandatory disclosure konvergensi IFRS”. Universitas Sebelas Maret, Surakarta, Makalah Simposium Nasional Akuntansi XV, Aceh.

Rosenstein, S. \& J. G. Wyatt. (1990). Outside directors, board independence, and shareholder wealth. Journal of Financial Economics, 26, 175-192.

Sagala, W. (2013). Faktor-Faktor yang Berpengaruh Terhadap Environmental Disclosure. Skripsi Ekonomi, Univeritas Muhammadiyah Yogyakarta.

Sanjaya, T. (2013). Analisis Pengaruh Good Corporate Governance Corporate Environmental Disclosure. Skripsi. Universitas Diponegoro Semarang.

Sembiring, E. R. (2005). Karakteristik Perusahaan dan Pengungkapan Tanggung jawab Sosial: Studi Empiris pada Perusahaan yang Tercatat di Bursa Efek Jakarta. Makalah disampaikan pada Simposium Nasional Akuntansi VIII, Solo.

Setyawan, B., \& Zulaikha, (2012). Analisis Pengaruh Praktik Good Corporate Governance dan Manajemen Laba Terhadap Corporate Environmental Disclosure. (Studi Empiris pada Perusahaan yang Terdaftar di BEI dan PROPER Tahun 2008-2010). Diponegoro Jurnal of Accounting.

Suhardjanto, D., \& Miranti, L. (2008). Indonesian Environmental Reporting Index dan Karakteristik Perusahaan. Makalah Akuntansi Universitas Sebelas Maret. 
Suhardjanto, D., \& Permatasari, N. D. (2010). Pengaruh Corporate Governance, Etnis dan Latar Belakang Pendidikan Terhadap Environmental Disclosure. Jurnal Akuntansi. Universitas Sebelas Maret, Surakarta.

Suratno, I.B., Darsono \& Mutmainah. (2006). Pengaruh Environmental Performance terhadap Environmental Disclosure dan Economic Perfomance (Studi Empiris Pada Perusahaan Manufaktur yang Terdaftar di Bursa Efek Jakarta Periode 2001-2004). Simposium Nasional Akuntansi IX (Padang).

Ujiyantho, M. A. \& Pramuka, B. A. (2007). Mekanisme Corporate Governance, Manajemen Laba dan Kinerja Keuangan (Studi Pada Perusahaan Go Publik Sektor Manufaktur). Simposium Nasional Akuntansi X

Uwuigbe. (2011). The Effect of Board Size and Board Composition on Firms Corporate Environmental Disclosur; A Study of Selected Firms in Nigeria. Acta Universitas Danubius. 7(5), 164-176.

Wintoro, D. (2012). Eksploratori Tujuan Manajemen Keuangan Bisnis Hijau. Jurnal Keuangan dan Perbankan, 16(1), 27- 36. Jakarta : Pusat Riset Prasetiya Business School.

Zhegal, D. \& Ahmed, S. A. (1990). Comparasion of social responsibility information disclosure media used by Canadian firms. Accounting, Auditing \& Accountability Journal. 3: 38-53. 